Supporting Information:

\title{
Construction of Carbon Nanotube Sponges to Have High Optical Antireflection and Mechanical Stability
}

Hang Zhan, Qiang Qiang Shi, Guang Wu, Jian Nong Wang*

School of Mechanical and Power Engineering, East China University of Science and Technology, 130 Meilong Road, Shanghai 200237, China

*Corresponding author: Tel. 86-21-64252360, E-mail: jnwang@ecust.edu.cn 

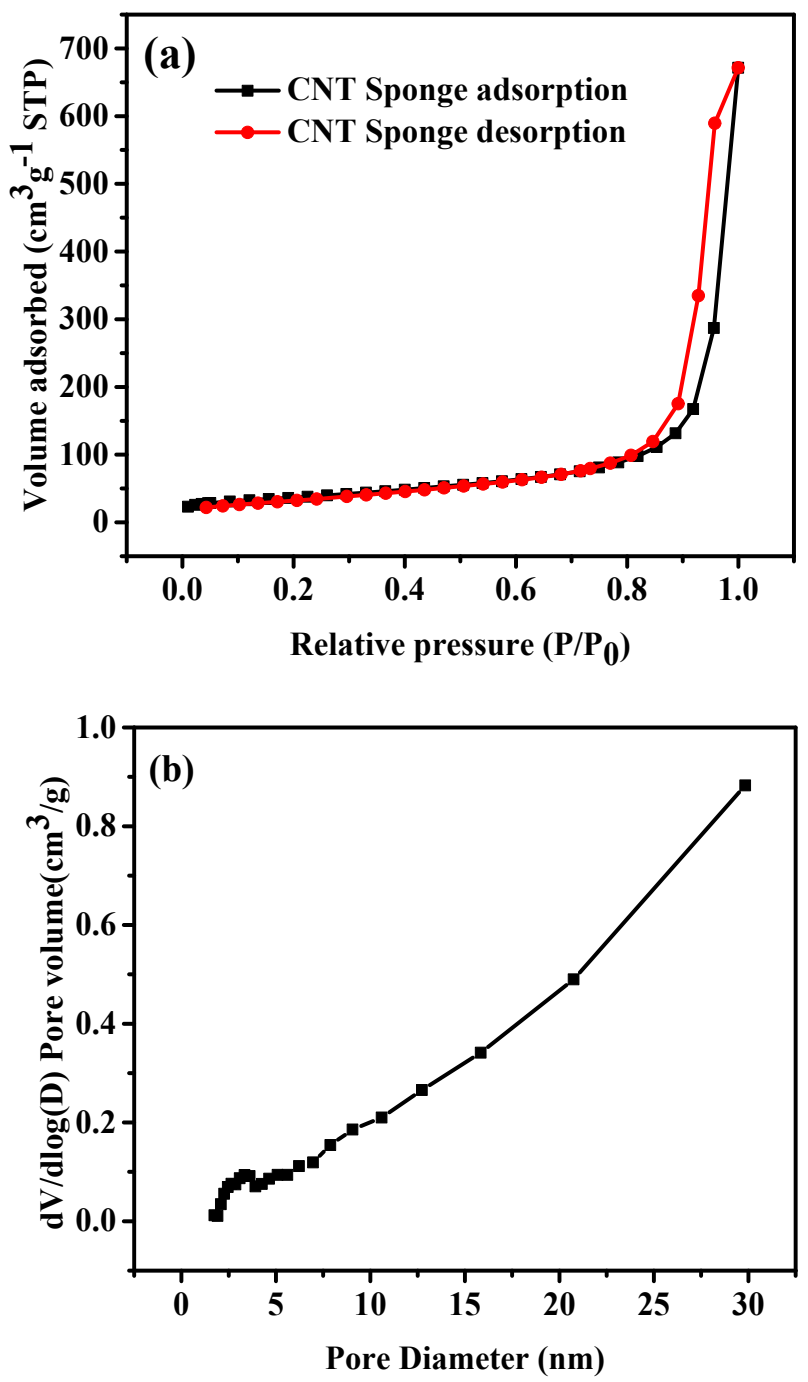

Figure S1. Characterization of the pore structure of the CNT sponge (25 $\left.\mathrm{ml} \mathrm{min}^{-1}\right)$.

(a) $\mathrm{N}_{2}$ adsorption-desorption isotherms; (b) Pore-size distribution curve 


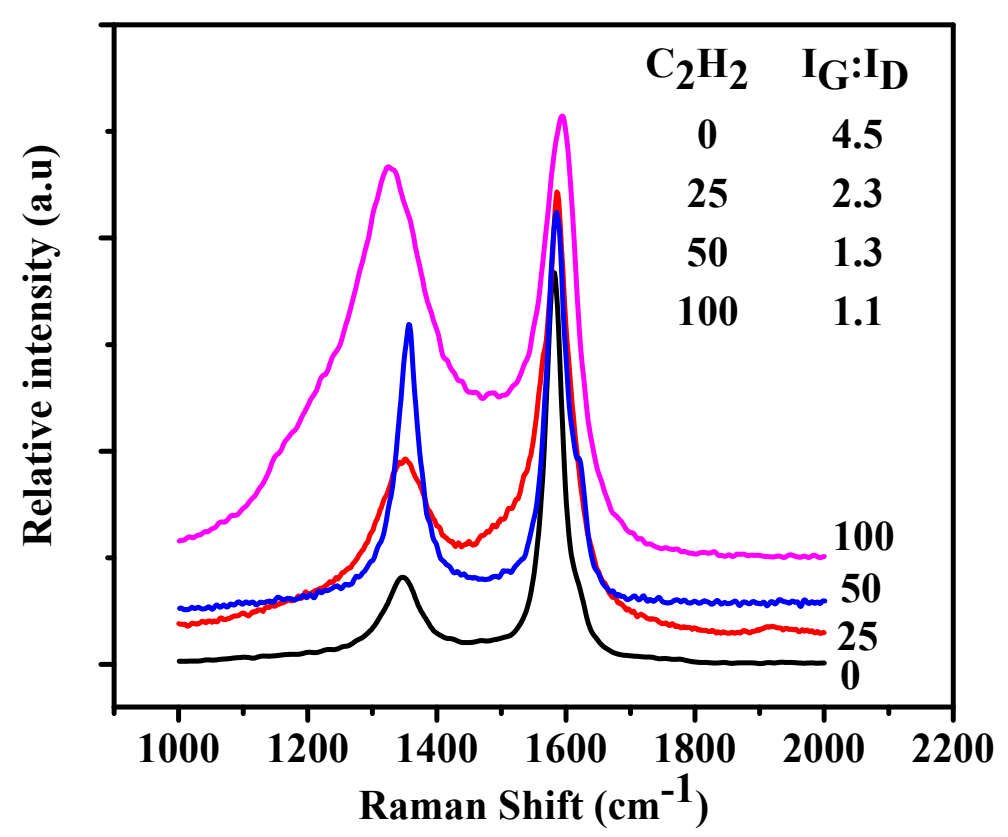

Figure S2. Raman spectra of the CNT samples formed at different $\mathrm{C}_{2} \mathrm{H}_{2}$ flow rates of $0,25,50$, and $100 \mathrm{~mL} \cdot \mathrm{min}^{-1}$.

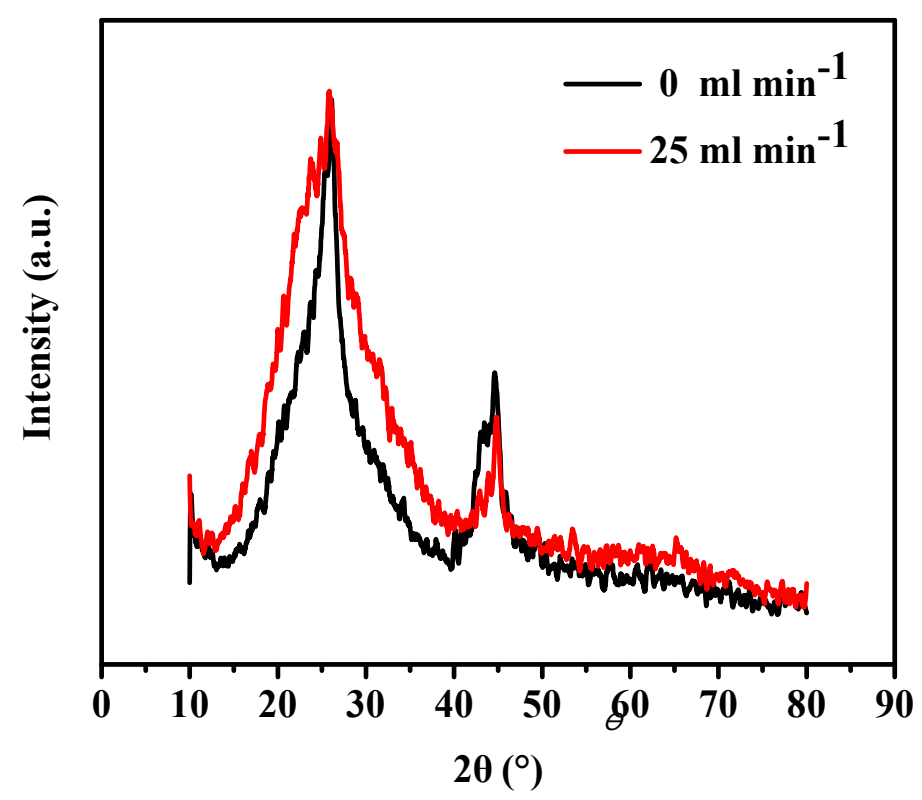

Figure S3. XRD spectra of the CNT samples formed at different $\mathrm{C}_{2} \mathrm{H}_{2}$ flow rates of 0 , and $25 \mathrm{~mL} \cdot \mathrm{min}^{-1}$. 


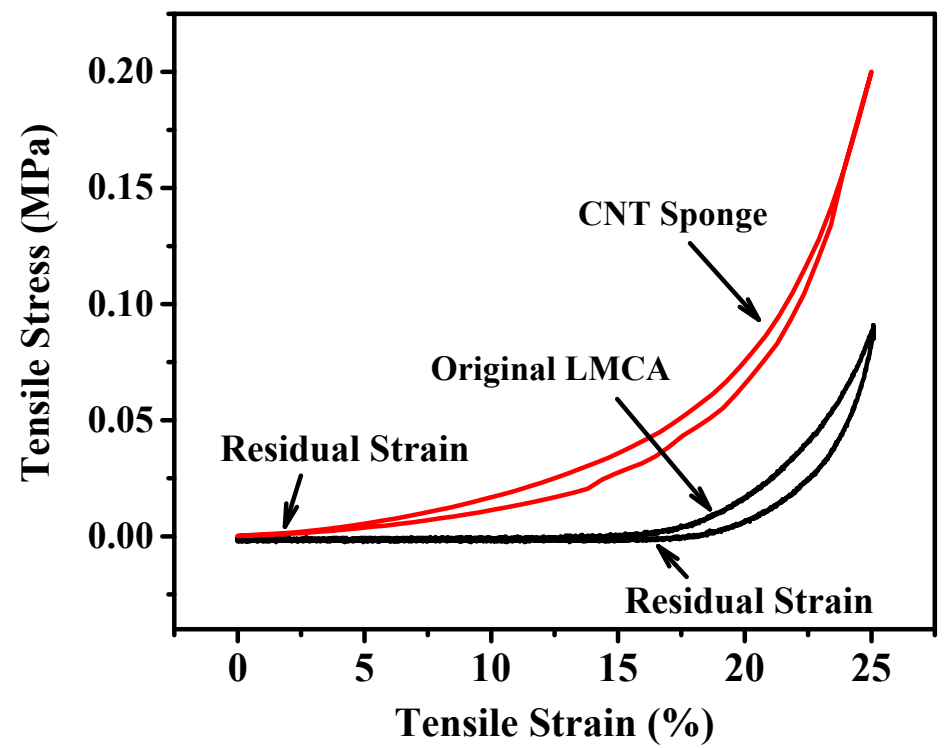

Figure S4. Tensile stress-strain curve of Original LMCA and CNT Sponge

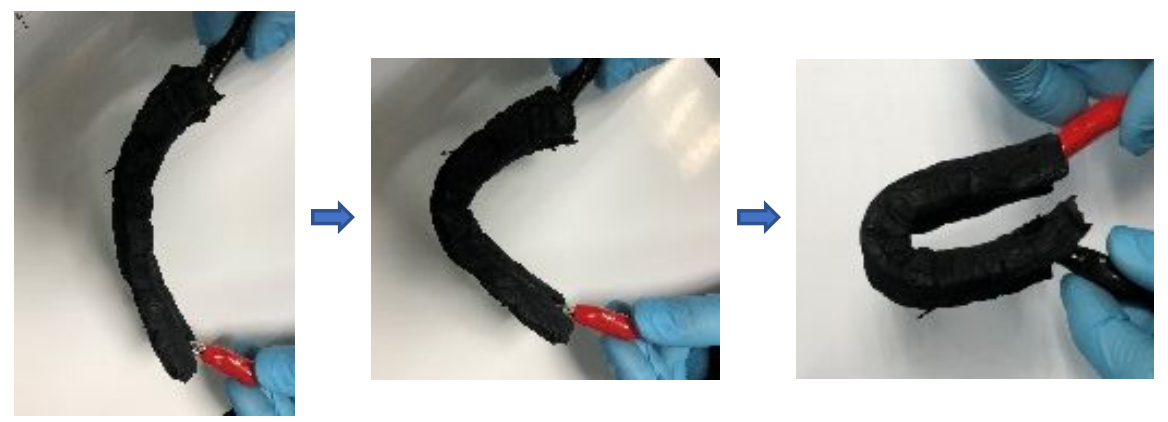

Figure S5. Bending demonstration of CNT sponge 


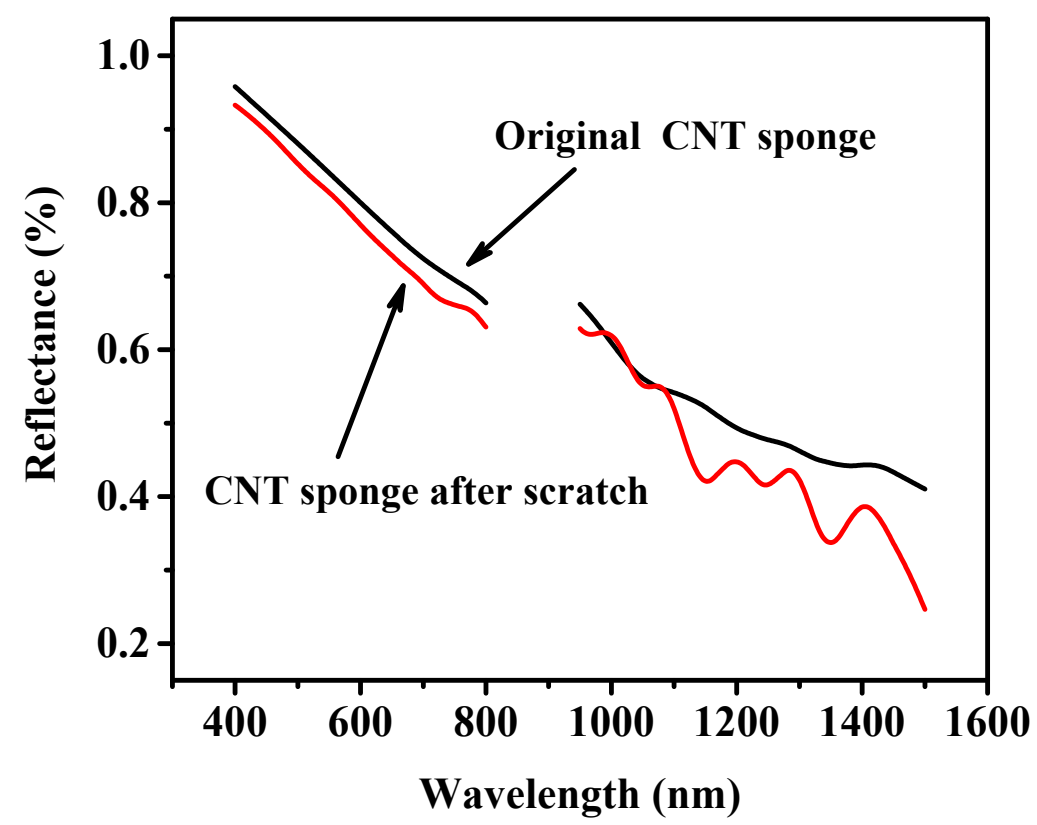

Figure S6. Reflectance comparison between the original $25 \mathrm{~mL} \mathrm{~min}^{-1}$ sample that after scratch by a razor blade.

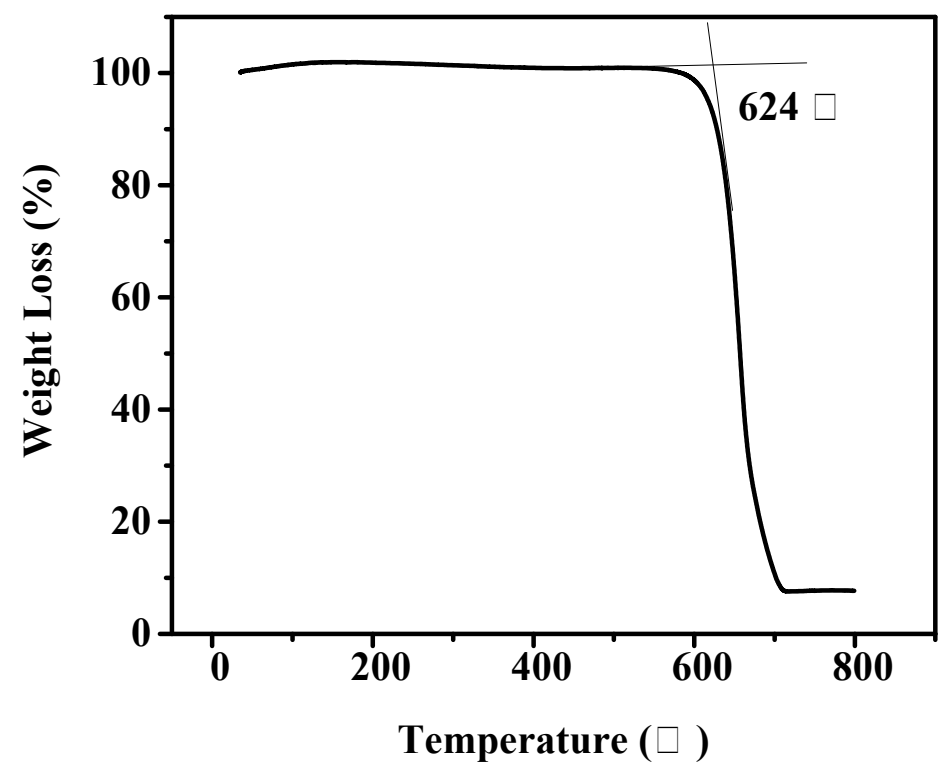

Figure S7. TG curve of the CNT sponge 


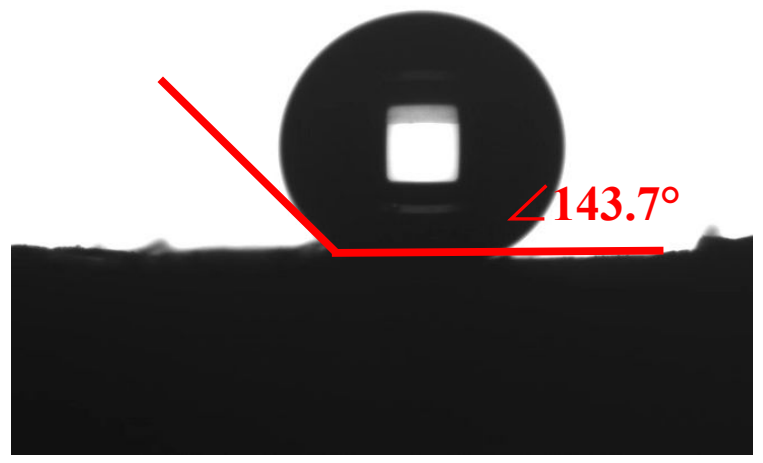

Figure S8. Water contact angle measurement of the CNT sponge 